\title{
BRIEF HISTORY OF NATURAL SCIENCES FOR NATURE-INSPIRED COMPUTING IN ENGINEERING
}

\author{
Nazmul SIDDIQUE ${ }^{\mathrm{a}}$, Hojjat ADELI ${ }^{\mathrm{b}}$ \\ ${ }^{a}$ School of Computing and Intelligent Systems, Ulster University, \\ Northland Road, Londonderry BT48 7JL, NI, UK \\ ${ }^{b}$ Departments of Biomedical Engineering, Biomedical Informatics, Civil, \\ Environmental, and Geodetic Engineering, Electrical and Computer Engineering, \\ Neuroscience and Neurology, The Ohio State University, \\ 470 Hitchcock Hall,2070 Neil Avenue, Columbus, Ohio 43210, USA
}

Received 14 Feb 2016; accepted 17 Feb 2016

\begin{abstract}
The goal of the authors is adroit integration of three mainstream disciplines of the natural sciences, physics, chemistry and biology to create novel problem solving paradigms. This paper presents a brief history of the development of the natural sciences and highlights some milestones which subsequently influenced many branches of science, engineering and computing as a prelude to nature-inspired computing which has captured the imagination of computing researchers in the past three decades. The idea is to summarize the massive body of knowledge in a single paper succinctly. The paper is organised into three main sections: developments in physics, developments in chemistry, and developments in biology. Examples of recently-proposed computing approaches inspired by the three branches of natural sciences are provided.
\end{abstract}

Keywords: natural science, physics, laws of motion, law of gravity, theory of relativity, big-bang, space-time, light, sound, hydrology, chemistry, chemical reaction, gravitational wave, black hole, galaxy, biology, evolution theory.

\section{Introduction}

The very simple question and the most unresolved problem hitherto in the history of science is the origin of life. There are many hypotheses on the origin of life. Many philosophers believed that the origin of life was a result of a supernatural event. Many scientists believed that life arose spontaneously from non-living matter in short periods of time.

In a very similar fashion, the most popular belief, even among many brilliant philosophers, is that the universe was created by a supernatural event. The question of whether the universe had a beginning in time was posed by philosopher Immanuel Kant (1724-1804) in 1781 (Kant 1781). Much later in the history of science, Edwin Hubble made a landmark discovery in 1929 that the distant galaxies are moving away (Hubble 1929). This discovery changed our conventional belief and made us think that the universe is expanding. The Russian physicist Alexander Friedmann made the same prediction some years before in 1922 (Friedmann 1922; see Hawking 1998). Extrapolating the expansion of the universe backwards in time using general theory of relativity yields an infinite density and temperature at a finite time in the past. This is known as singularity theory or big-bang singularity.
Behind all of the changes, adaptation, evolution and the ultimate motion of all the bodies in the universe, it is the dialectics of nature that put them, be it living or nonliving, in a process of development. In dialectics, phenomena are characterised by their abilities to change. The changes are initiated by contradiction. The contradiction is the sole basis of dialectics. Dialectics has been used by two thinkers, Aristotle and Hegel (Engels 1934). The dialectics for the present-day natural sciences was introduced by German philosopher Friedrich Hegel (1770-1831). Inspired by Hegel, a popular natural philosophical movement in the early $19^{\text {th }}$ century, the concept of dialectics of nature was first applied by Friedrich Engels (1820-1895) in 1870 s as a method of explaining the evolutionary processes occurring in the nature and as a tool for analysing the science, the science of the historical development of the human thought, the society, their inter-connection in general and revealing the metaphysical conceptions in natural sciences and complex relationship among them. The two events, the origin of life (i.e. origin of species) and the origin of the universe (i.e. big-bang singularity), and their evolution over time are related in a metaphorical way are explained with the help of the dialectics of nature.

Corresponding author: Nazmul Siddique

E-mail:nh.sidique@ulster.ac.uk 
The precise motions of the planets along with their moons in their destined orbits, the innumerable suns and solar systems bounded by outermost stellar rings of the Milky Way, motion of the stars and galaxies, supernova phenomena, creation of new stars, gravitational collapse of stars, black holes in the deep space of the universe, the interplay of gravitational, magnetic and electrical forces are among many examples of the nature that evolved over billions of years. Today's natural sciences owe much to Copernicus who on his death bed in essence emancipated the natural sciences from ecclesiastical superstition in the $16^{\text {th }}$ century. Since then the natural sciences made giant strides in the fields of mathematics, mechanics, astronomy and dynamics. Much of the advancements owe to Kepler and Galileo followed by Newton.

Phlogiston theory in chemistry dominated the $18^{\text {th }}$ century. Antoine Laurent Lavoisier freed chemistry from alchemy by discovering the law of conservation of mass that states that the mass can neither be created nor be destroyed. It changes from one form to another. John Dalton introduced atomic theory in chemistry and postulated that atoms are regrouped to form different substances during chemical reactions. That was the beginning of modern chemistry.

Biology arrived at the second half of the $18^{\text {th }}$ century through collection of vast botanical and zoological samples, naming and classifying them mainly owing to Carl Linnaeus. Scientists conducted the essential investigation and comparison of various forms of life, geographical distribution and condition of existence. It took the scientists another century investigating the species by putting them one after another and analysing the historic development that led Charles Darwin to conclude his evolution theory of the origin of species in the $19^{\text {th }}$ century. He established that all species of life have evolved over time from common ancestors of simple organisms toward higher complexity.

This paper presents a brief history of the development of the natural sciences and highlights some milestones, which subsequently influenced many branches of science, engineering and computing as a prelude to nature-inspired computing which has captured the imagination of computing researchers in the past three decades. The final goal of the authors is adroit integration of three mainstream disciplines of the natural sciences, physics, chemistry and biology, to create novel problem solving paradigms. The paper is organised into three main sections: developments in physics, developments in chemistry, and developments in biology. Computing paradigms inspired by these branches of sciences are briefly noted.

\section{Development in physics}

The study of nature has its beginning in the antiquity. The three mathematicians during the Hellenic age who became well-known above most of their predecessors and successors of the time are Euclid of Alexandria, Archimedes of Syracuse and Apollonius of Perga (Boyer
1991). Antiquity had enlightened the human knowledge and civilisation with Euclidean geometry, Archimedes' lever and hydrostatic principles, and Apollonius' conics and Ptolemaic solar system. The $12^{\text {th }}$ century Persian mathematician, astronomer, and geographer, al-Khwarizmi (Latinized as Algoritmi) introduced the decimal point number system and first systematic solution of linear and quadratic equations and is considered the original inventor of algebra. The word algorithm originates from his Latin name, Algoritmi.

In Europe, the most fundamental natural science, the mechanics of terrestrial and heavenly bodies was developed in the $15^{\text {th }}$ century. The basic features of many fundamental mathematical methods were developed in the $16^{\text {th }}$ and $17^{\text {th }}$ century such as logarithms by John Napier (1550-1617) (Hobson 1914; see Napier 1969), analytical geometry by Rene Descartes (1596-1650) (Forbes 1777; see Descartes 1954), differential and integral calculus by Pierre de Fermat ${ }^{1}$ (1601-1665) (Anderson 1983), Sir Isaac Newton (1642-1727) (Cohen 1971; see Newton 1972) and Gottfried Wilhelm Leibnitz (1646-1716) (Child 1920; see Leibnitz 1975). The eighteenth century Europe saw a number mathematical prodigies like Leonhard Euler (1707-1783) with significant contribution to the development of mathematics (Grattan-Guinness 1971), Joseph-Louis Lagrange (1736-1813) with tremendous contribution to development of analytical mechanics, calculus of variations and celestial mechanics (Fraser 1983; see Lagrange 1901), Pierre Simon Laplace (17491827) contributed to celestial mechanics (see Laplace 1966), Adrien-Marie Legendre (1752-1833) contributed to geometry, differential equation, theories of functions and numbers (Boyer 1991) and Jean Baptiste Joseph Fourier (1768-1830) contributed to mathematical physics (Grattan-Guinness 1972; Jourdian 1912).

Nicholas Copernicus (1473-1543) accomplished the first consistent theory of the heliocentric solar system placing the Sun in the centre (Hallyn 1993). Johannes Kepler's (1571-1630) described the laws of planetary motions without reference to governing forces (Brasch 1931; Hallyn 1993). Galileo Galilei (1564-1642), well-known for his observations, introduced the concepts of modern dynamics (Drake 1973; see Galilei 1960) and Isaac Newton formulated the general laws of motion and the relation between the forces acting on a body and the motion of the body. Galileo also made major progress in understanding the properties of natural motion and simple acceleration motion of earthly bodies. Galileo showed through experimentation that the earth's gravitational acceleration is independent of the body mass. During the $16^{\text {th }}$ and $17^{\text {th }}$ centuries, several other scientific contributions to the problem of earthly and celestial motion set the stage for Newton's gravitational theory. These achievements were remarkable in this era with the postulation of the major

\footnotetext{
${ }^{1}$ Pierre Laplace said about Fermat "Fermat - the true inventor of differential calculus".
} 
theories and explanations to the physical phenomena in terms of basic laws of motion and gravitation. This gave birth to some trends in physics, especially the field that was later named mechanics.

\subsection{Laws of motion}

Isaac Newton published his three laws of motion in his book of Mathematical Principles of Natural Philosophy in 1687 (see Newton 1999). The three physical laws laid the foundation of classical mechanics which describe the relationship between a body and the forces acting upon it, and its motion in response to said forces. The laws cover the law of inertia, the law of force and the law of action and reaction. The first law of inertia states that if a body is at rest or moving at a constant speed in straight line, it will remain at rest or keep moving at constant speed in the same direction. The second law of force states that the acceleration $a$ (also defined as the rate of change of velocity) is directly proportional to applied force $F$ and inversely proportional to mass $m$ of the body. The third law also referred to as the law of action and reaction states that every action has an equal opposite reaction.

\subsection{Law of gravitation}

Newton also published the law of universal gravitation in year 1687 in his book of Mathematical Principles of Natural Philosophy. According to the law of universal gravitation, everybody in the universe attracts every other body. The attraction force between two bodies is directly proportional to the product of their masses and inversely proportional to the square of the distance between them. The modern quantitative science of gravitation began with Newton's law of universal gravitation, which has been expressed in many different ways over nearly three centuries until Einstein's work in the early $20^{\text {th }}$ century. Newton's theory is of sufficient accuracy for most applications hitherto.

Still there were unexplained questions about what gave rise to the orbits of the planets. The highest general idea the natural science attained was that of the purposiveness of the arrangements of the nature, which Isaac Newton had explained as the divine first impulse imposed by God. This now obsolete idea dominated the first half of the nineteenth century. It was the German philosopher Immanuel Kant (1724-1804) who in his book titled "Allgemeine Naturgeschichte und Theorie des Himmels" laid out the nebular hypothesis (see Kant 1781). The nebular hypothesis states that the solar system formed from a large cloud of gas called nebula. Kant's discovery was a point of departure from all previous theories. Years later Pierre Simon Laplace (1749-1827) provided a foundation which led to the discovery of glowing nebular masses and motion of the stars (Eisberg 2003). His typical study was the conditions for equilibrium of a rotating fluid mass, a subject closely related to the nebular hypothesis of the origin of the solar system. According to the theory of
Laplace, the solar system evolved from an incandescent gas rotating about an axis. The gas contracted as it cooled causing rotation with higher speed according to the law of conservation of momentum. As the speed increased, the successive rings broke off from the outer edge to condense and formed the planets. The rotating sun constitutes the remaining central force of the nebula. How a solar system develops from an individual nebular mass was shown by Laplace mathematically.

The innumerable suns and solar systems of our island universe, bounded by the outermost stellar rings of the Milky Way, developed by contraction and cooling from the swirling, glowing masses of vapour, and the laws of motion of provided an insight into proper motion of the stars. Compellingly astronomy was accepting the existence of the dark bodies that is not merely planetary in nature. A part of the gaseous nebular patches belongs to the stellar system as suns not yet formed, which provides sufficient clues to the existence of other distant independent island universes at an early stage of development. Thus the astronomy, the oldest of all natural sciences, started flourishing on stronger mathematical and theoretical foundations.

The theory of astronomy, later professional astronomy often considered to be synonymous with astrophysics, suggests that a sufficiently massive object like star must inevitably collapse under its own gravitational selfattraction upon exhausting its nuclear fuel. It expels part of its material in a supernovae explosion but core of these collapsed stars ends in a new super dense state of matter called neutron star or collapse infinitely toward a singularity which causes the properties of the surrounding space to change due to the enormous strong gravitational fields. The gravitational field is so strong that it attracts everything into itself and swallows them and even light cannot escape from it making it dark and invisible to the outside world. Such black voids in space are known as black holes. Black hole was first announced by John Michell in 1783 (Hawking 1998; Schaffer 1979). A similar phenomenon was confirmed by Pierre-Simon Laplace in 1795 independently of Michell's work.

The form of motion of matter at first prevailing is what we call heat. At some high temperatures under certain conditions, the heat can then be transformed into electricity or magnetism. It is postulated that the mechanical motion taking place in the sun arises solely from the conflict of heat with gravity (Engels 1934).

The theory of gravitation not only has huge impact on many scientific inventions in the later centuries but also many other nature-inspired conceptual framework with roots in gravitational kinematics, a branch of physics that models the motion of masses moving under the influence of gravity in the recent years. Based on the laws of gravitation and natural physical forces, number of computing algorithms has been proposed by researchers.

Inspired by the gravitational kinematics and models the motion of masses moving under the influence of grav- 
ity a nature-inspired conceptual computing framework and optimization algorithm has been developed called Central Force Optimization (CFO). Siddique and Adeli (2015d) present a review of CFO, its variants, and applications to engineering problems. Example applications include electric circuit design, antenna design, water pipe network design, and training of artificial neural networks. Another computing algorithm inspired by the gravitational kinematics is the Gravitational Search Algorithm (GSA). A thorough review of GSA and its variants is presented in a recent article by Siddique and Adeli (2016a, 2016b). Other less well-known variants are Artificial Physics Optimization (Spears, D. F., Spears, W. M. 2003), Space Gravitation Optimization (Hsiao et al. 2005), Integrated Radiation Search (Chuang, Jiang 2007).

\subsection{Transformation between heat and mechanical energy}

Christiaan Huygens (1629-1695) introduced an important quantity which later became known as energy (Andriesse 2005; Cercignani 1998). When a point mass subjected to a force moves along a path in the direction of the force, it increases a quantity called energy which depends on the mass and the velocity. This energy is known as kinetic energy. Descartes introduced the concept of momentum and maintained that this quantity was conserved on grounds of metaphysical speculations. It was Huygens who defined momentum as the product of the mass and square of the corresponding velocity. Benjamin Thompson (17531814) had observed the frictional heat generated by boring cannon at the arsenal in Bavaria. He also observed that a huge amount of energy was lost through production of heat. Thompson concluded that there should be a direct relationship between the loss of mechanical energy and the heat produced. He proposed to assume that heat is a form of energy which is transformed from mechanical energy (Thompson 1798). Thus the principle of conservation of energy was established.

During the same time, the concept and the term "work" emerged in connection with the development of applied mathematics used by Lazare Carnot (1753-1823) (Gillespie 1971). Meanwhile the industrial revolution occurred in England with the invention of steam engine by James Watt (1736-1819) (Dickinson 1939). This was another manifestation of conversion of heat energy into mechanical force. William Robert Grove ${ }^{2}$ (1811-1896) published his paper on the correlation of physical forces in 1846 where he anticipated the general theory of the conservation of energy (Grove 1874). Sadi $^{3}$ Carnot (1796-1832) argued that heat is the result of motion (see Carnot 1824). He showed in his book published posthumously in 1878 that the motive power of heat is a uni-

\footnotetext{
${ }^{2}$ Grove's book "The Correlation of Physical Forces" was published in 1846 based on the lectures he gave at the London Institute in January 1842.

${ }^{3}$ Sadi Carnot was a son of Lazare Carnot, who died of cholera at the age of 36 .
}

versal function of temperature and proposed the Carnot process which is the basic principle of thermodynamics. A debate emerged out at that time that the total heat must always be exactly proportional to the kinetic energy. Another milestone of discovery in science was the confirmation and experimental proof of the transformation of heat into mechanical force and mechanical force into heat by Julius Robert Mayer (1814-1878) (Mayer 1842) and James Prescott Joule (1818-1889) (Joule 1850). It was not until $19^{\text {th }}$ century that the law of the conservation of energy was first recognised as a law of nature.

The law of thermodynamics states that there are two kinds of energy in any physical system: mechanical and thermal. The sum may change because one performs work on the system or supplies heat to the system. The first law of thermodynamics states that the change in total energy equals the work performed plus the heat supplied to the system. The second law of thermodynamics is the equilibrium of entropy which states the entropy can never be decreased in a thermally isolated system. The second law also states that there exists no process in which heat is transformed from a colder body to a warmer body without some other related change occurring at the same time. This implies that there is a thermodynamic quantity 'temperature' which alone decides the direction of heat transfer. The ideas of thermodynamics became popular among scientists of different disciplines. They were extended to continuous media and mechanics of continua developed earlier by Leonhard Euler and Augustin Louis Cauchy (1789-1857) (Truesdell 1992). Hermann Ludwig Ferdinand von Helmholtz (1821-1894) showed the conservation of energy and how it is preserved in electrodynamics, chemical thermodynamics, and mechanical thermodynamics (Helmholtz 1871).

The study of thermodynamics enriched the available tools but another theory that of electromagnetism was still needed. Electric phenomena of attraction and repulsion that come out of friction are part of everyday experience which was understood in terms of electric charges in the early $17^{\text {th }}$ century. William Gilbert (1544-1603) attributed electrification of body by friction. Gilbert is credited for the term electricity used in modern times (Gilbert 1600). The observations were organised in form of theory by Benjamin Franklin (1707-1790) who attributed "+" sign for positive charge and "-" sign for negative charge. Some materials are charged positively and some are negatively (Elliott 1993, Inan, U. S., Inan, A. S. 1999). Charles-Augustin de Coulomb (1736-1806) performed experiments with his own torsion balance (also known as Coulomb torsion balance ${ }^{4}$ ) in 1785 and demonstrated the law of electric force, which is later known as Coulomb's law (Gillmor 1971).

While the science of electrostatics had been progressing and fundamental laws were becoming clearer,

\footnotetext{
${ }^{4}$ Coulomb torsion balance is an instrument that enables verifying experimentally the quantitative law of interaction between electrical charges.
} 
Luigi Galvani (1737-1798) noticed that electrical charge produced by machines caused muscular contraction in a dissected frog (Marco 1998). It was identified in further experiments that electric charge is transported by the metal from the nerve to the muscle causing the contraction. This simple fact inspired Alessandro Volta (1745-1827) to the invention of electrical battery in 1799 , which was a milestone for this new field of electricity (Pancaldi 2003). This simple fact proved that electricity can be generated chemically. A relationship thus established between physics and chemistry. This also encouraged scientists to develop atomistic view in chemistry. Heating effects caused by electrostatic discharges had been known for some time. There had been sporadic reports that iron objects become magnetised when struck by lightning. Hans Christial Oerstedt (1777-1851) was the first to observe that magnetic compass needle was influenced by currents in neighbouring conductors in 1820 (Oerstedt 1820). Around the same time, Andre Marie Ampere (1775-1836) showed that two parallel wires carrying electric current attracted each other if the current flowed in the same direction while wires repelled each other when the current flowed in opposite directions (Ampere 1820). Jean-Baptiste Biot and Felix Savart in 1820 repeated Oersted's experiments and formulated a compact law of static magnetic fields generated by current in a circuit, which later became known as Biot-Savart law (Biot, Savart 1820). The Biot-Savart law is the first quantitative analysis of this phenomenon and the most basic law of magnetostatics. In the following years, Ampere undertook the most thorough treatment of the subject, formulated this phenomenon in mathematical terms and defined Ampere's law of magnetic force. He also postulated that magnetism itself was due to circulating current. Ampere's law founded the science of electric currents.

George Simon Ohm (1787-1854) investigated the conductivity of electricity and established a relationship between potential difference, current flow, and resistance published in 1827, which later became known as Ohm's law (Gupta 1980). A definition of electric resistance of wire was thus formalised. The relationship between electric currents and heat was investigated by James Prescott Joule (1818-1889) and formulated in its final form of theory in 1841 (Joule 1841). Many years after establishment of Coulomb's law, the last seal to experimental picture came from Michael Faraday (1791-1867) with a fundamental contribution to electromagnetic induction and diamagnetism (Faraday 1855). Faraday understood electric and magnetic fields in terms of lines of force and concluded that an electric field is essentially a field of force. Faraday set up an experiment and deduced that a magnetic field could generate a steady current. These experiments enabled Faraday to formulate his famous law of electromagnetic induction widely known as Faraday's law. Faraday's law showed that steady current can be generated by changing magnetic field where mechanical energy is applied to change the magnetic field and pro- duce induced voltage. Thus the world's first direct-current generator was invented. Wilhelm Weber (1804-1891) perfected the theory of electrodynamics such that all the electromagnetic phenomena known up to that point of time, i.e. Coulomb's law, Ameper's law and Faraday's law, could be explained (Weber 1848; Hunt 2003). Faraday was not well-versed in advanced mathematics of the time. It was James Clark Maxwell (1831-1879) who took the work of Faraday and others, and formulated them in a set of equations that later became known as the complete classical theory of electromagnetism and considered as the axioms of electrodynamics (Maxwell 1892). $\mathrm{He}$ described both electric and magnetic fields and the laws of their mutual changes in the mathematical form of partial differential equations. He showed the changes of differentials in several dimensions with respect to their neighbours. Electrodynamics thus proved to be a local action theory. He predicted the existence of electromagnetic waves and inferred the electromagnetic nature of light. The existence of electromagnetic waves was experimentally confirmed 23 years later by Heinrich Rudolf Hertz (1857-1894) in 1887 (Hertz 1888). Electrical engineering emerged as a discipline of study.

At the beginning of the $20^{\text {th }}$ century Max Planck (1854-1947) introduced the quantum theory, which revolutionized human understanding of atomic and subatomic processes (Planck 1900a, 1900b). Later Albert Einstein (1879-1955) extended the quantum theory to light. In the year 1905, known as Annus Mirabilis, Albert Einstein published four ground-breaking articles in the scientific journal of Annalen der Physik. They pertain to the photoelectric effect which gave rise to quantum theory, Brownian motion, the special theory of relativity, and mass-energy equivalence $\left(E=m c^{2}\right)$. The paper on electrodynamics of moving bodies resolved Maxwell's equations for electricity and magnetism with the laws of mechanics. It introduced major changes to mechanics close to the speed of light. This later became known as Einstein's special theory of relativity which has further implications that include the time-space frame of a moving body appearing to slow down and contract. In the paper on mass-energy equivalence, Einstein proved $E=m c^{2}$ by applying the theory of special relativity. Einstein's 1905 work on relativity remained controversial for many years. The paper on the motion of small particles suspended in a stationary liquid explained the empirical evidence of atomic theory, known as Brownian motion with implication in statistical physics. The paper on heuristic viewpoint of production and transformation of light, known as photoelectric effect, suggested that energy is exchanged only in discrete amounts or quanta with pivotal influence on the development of quantum theory. These four works contributed substantially to the foundation of modern physics and changed the prevailing views on space, time, and matter.

It is now evident from the study of all sciences that energy is convertible. Motion had been linked to heat. 
Heat is linked to another form of motion - wave motion or light. Chemical change had been converted into current and back, current into magnetism and back, and heat into electricity and back, and electric current and chemical reaction into heat. In many cases, heat is the final form of energy.

In 1915, Einstein published his famous and revolutionary General Theory of Relativity (Einstein 1915, 1916). Space and time were no longer separate and independent entities. Instead, they were just different directions in a single object called space-time. This space-time is not flat, but is deformed and curved by the matter and energy in it. Thus, the idea of black hole was rediscovered in 1916. Karl Schwarzschild (1873-1916) then solved Einstein's equations for the case of a black hole (Schwarzschild 1916), which he envisioned as a spherical volume of warped space surrounding a concentrated mass and completely invisible to the outside world.

In 1939, Robert Oppenheimer (1904-1967) and Hartland Snyder (1913-1962) published the first detailed treatment of a gravitational collapse using Einstein's theory of gravitation (Oppenheimer, Snyder 1939). This led to the idea that such an object might be formed by the collapse of a massive star that leaves behind a small and dense remnant core. If the core's mass is more than about three times the mass of the Sun, the equations showed, the force of gravity overwhelms all other forces and produces a black hole. The most common black holes are probably formed by the collapse of massive stars. Larger black holes are thought to be formed by the sudden collapse or gradual accumulation of the mass of millions or billions of stars. Many galaxies are believed to have such super massive black holes at their centres. There is a black hole at the centre of our Milky Way galaxy known as Sagittarius A* which has a mass four million times that of the solar mass. Most astronomers believe that the black holes in the centres of galaxies grew by swallowing stars and nebular gases in the process. The gravitational force is so strong that even no light comes from the black holes in active galaxies to explain their growth. Astrophysical discoveries such as quasi-stellar objects, pulsars, and the apparent gravitational radiation pulses being received from the galactic centre indicate that unusual astrophysical objects containing intense gravitational fields may exist in the universe.

There are three fundamental questions in physics. How did the Universe begin? Does time have a beginning and an end? Does space have edges? According to Einstein's theory of relativity, space, time and matter are connected together. Einstein's theory of relativity provided some answers to these very old questions with three startling predictions: the universe is expanding from a Big Bang, black holes do distort space and time, and the dark energy could be pulling the space apart, sending the galaxies forever beyond the edge of the visible universe.

Most scientists believe that all the matter, energy and space in the universe were once squeezed into an infinitesimally small volume. There was a cataclysmic explosion which created the universe. The space, time, energy, and matter all came into being at an infinitely dense and infinitely hot gravitational singularity, and began expanding at once. The explosion became known as the Big Bang which is considered to be the theory behind the birth of the universe. The Big Bang was neither Big (the universe was smaller than the size of a proton), nor a Bang (it was more of a snap or a sudden inflation). It is also believed that since the Big Bang, the universe has been expanding. However, scientists also believe that this expansion will not continue forever. All matters will collapse into the biggest black hole pulling everything within it which is referred to as Big Crunch.

The big bang theory was finally proved by Roger Penrose and Stevens Hawking in 1970. In other words, the big-bang singularity refers to the birth of the universe and explains the subsequent evolution of the universe. The theory became very popular with the publication of the book "A Brief History of Time: From the Big Bang to Black Hole" by Stevens Hawking in 1987. The evolution of the universe resulted from the dialectics of the forces where the heavenly bodies in the universe such as moons, planets, suns, stars, galaxies, and nebular and stellar materials attract each other and sets them in motion.

Galaxies are structures within the universe formed by the mutual gravitation of matter into bound systems of stars, stellar remnants, interstellar gas and dust, and dark matter (Hawking 1998; Sandage 1975). Galaxies range from dwarfs with just a few thousand stars to one hundred trillion stars. They are all orbiting around their galaxy's own centre of mass. Our galaxy has hundreds of billions of stars, enough gas and dust to make billions of more stars, and at least ten times as much dark matter as the sum of all the stars and gas together which are all held together by gravity. The modern picture of the universe dates back to 1924 when Edwin Hubble showed that there are many other galaxies in the universe. To date, approximately 170 billion galaxies are known in the observable universe. The space between galaxies is filled with interstellar gas and dust and dark matter. The majority of galaxies are gravitationally organized into associations known as galaxy groups, clusters, and superclusters. Galaxies can be categorized according to their visual morphology into three groups: elliptical, spiral, and irregular (Sandage 1975). Elliptical-shape galaxies are early type galaxies and exhibit a larger range of mass and less angular variation in brightness compared to other galaxies. A spiral galaxy is a certain kind of galaxy originally described by Hubble in 1936 (Hubble 1936). The characteristic beauty of this type of galaxy is its spiral structure. The spiral arms are sites of ongoing star formation and are brighter than their surroundings.

Albert Einstein determined that the laws of physics are the same for all non-accelerating observers, and that the speed of light in a vacuum is independent of the motion of all observers. This theory is known as the spe- 
cial theory of relativity published in 1905 which provided a new framework and the concept of space and time in physics (Einstein 1905). Einstein worked for 10 years on the development of the theory of general relativity and presented his work to the Prussian Academy of Science in 1915. This is now known as the Einstein field equations. These equations form the core of Einstein's general theory of relativity and specify how the geometry of space and time is influenced by whatever matter and radiation are present. According to this theory, a massive object (e.g. an asteroid) causes curvature in the geometry of the space-time due to the gravitational field. This is felt as gravity (Einstein 1915, 1916).

Einstein $(1915,1918)$ first predicted the gravitational waves on the basis of his theory of general relativity (Einstein 1916). Binary star ${ }^{5}$ systems composed of white dwarfs $^{6}$, neutron stars ${ }^{7}$, or black holes ${ }^{8}$ are sources of gravitational waves. The existence of gravitational radiation has been proved indirectly by Hulse and Taylor. The measurement of the Hulse-Taylor binary system suggests gravitational waves are more than mathematical anomalies. They detected pulsed radio emissions from a pulsar in a binary star system, and also discovered that the changing orbit of the binary star system is matched with the loss of energy due to release of the gravitational radiation from the binary star system (Weisberg, Taylor 2004). It is believed that gravitational radiation can occur only for an accelerating object and cannot occur for a static object or to non-spinning object at constant velocity.

Electromagnetism and electrostatics contributed to many inventions in the $19^{\text {th }}$ and $20^{\text {th }}$ century. In recent years, a number of computing algorithms have been proposed based on the principles of electromagnetic force and interaction between charged particles based on Coulomb's law, for example, Electromagnetism Optimisation (Birbil, Fang 2003) and Hysteretic Optimisation (Zaránd et al. 2002). There are also astrophysics-based algorithms such as big bang-big crunch (Erol, Eksin 2006), black hole search (Hatamlou 2013), and galaxy-based search (Hosseini 2011).

\subsection{Light}

The idea that light emitted from a source is reflected from the object and enters into eye and creates a sense of vi-

\footnotetext{
${ }^{5}$ A binary star is a star system consisting of two stars orbiting around their common center of mass.

${ }^{6}$ A white dwarf is a stellar remnant composed mostly of electron-degenerate matter and very dense. A white dwarf's mass is comparable to that of the Sun with a volume comparable to that of the Earth.

${ }^{7}$ A neutron star is a stellar remnant that results from the gravitational collapse of a massive star. Neutron stars are the densest and the smallest stars known to exist in the universe. They can have radius of only about $12-13 \mathrm{~km}$ and mass of about two times that of the Sun.

${ }^{8}$ A black hole is a mathematically defined region of space-time exhibiting such a strong gravitational pull that no particle or electromagnetic radiation can escape from it.
}

sion was explained by Epicurus of Greece. Ptolemy in Alexandria measured the angles of incidence and refraction of light ray going from one transparent medium to another. He correctly deduced that the ray is bent toward the normal. Willebrord Snell (1580-1626) first established the so-called sine law that gives the index of refraction (Pledge 1939). The index of refraction is a measure of the change in direction for light passing through a transparent medium. The laws of reflection and refraction were postulated by Pierre de Fermat (Pledge 1939). It states that the ray of light traverses in a straight line that takes the minimum time. While Isaac Newton supported corpuscular theory, others supported the wave theory of light which indicates propagation through universal medium called ether. Ether theory became void when James Maxwell proposed the electromagnetic theory of light. Maxwell's wave theory was based on continuous medium. Max Planck demonstrated it is necessary to postulate that radiant-heat energy is emitted in quanta. In 1905, Einstein showed the wave-particle duality in the nature of light in the theory of photoelectric effect (Einstein 1905). The basic idea of Snell's law has been used to develop a ray optimization (RO) algorithm (Kaveh, Khayatazad 2012).

\subsection{Sound and Sonics}

Sounds are audible phenomena in the nature produced by various means (Deleforge et al. 2015). To perceive the sounds created in the environment, hearing organ in the animal species has evolved which is one of the most crucial means of survival for them. Speech, a form of sound, is one of the most distinctive features of human. Sound can propagate in the air, liquids, and solids. The branch of physics that deals with understanding of sound is called acoustics. Pythagoras ( $6^{\text {th }}$ century BC) showed that pitch of a musical sound depends on the frequency of vibration of the sound producing object. A fundamental feature of regular sounds, e.g. speech, music etc., is their frequency (i.e. cycles per second) expressed in $\mathrm{Hz}$ (i.e. Hertz). Sound less than $20 \mathrm{~Hz}$ is called infrasonic, and sound greater than $20 \mathrm{kHz}$ is called ultrasonic. Normal human ear can hear sound within the interval of $20 \mathrm{~Hz}-20 \mathrm{kHz}$. Little was reported in the middle ages except attempts for measurements of velocity of sound. Isaac Newton suggested the theoretical measure of the velocity of sound and proposed that the velocity of sound in air should be the square root of the ratio of atmospheric pressure to density. Newton's formulation of sound propagation in the air was based on constant temperature. Pierre-Simon Laplace gave the correction to Newton's formulation assuming that compressions and rarefactions (opposite of compression) in sound propagation in the air do not take place at constant temperature. Laplace proposed that the ratio of pressure to density should be multiplied by that of specific heat to obtain velocity of sound in air. Jean Le Rond d' Alembert (1717-1783) proposed the wave motion in 1747 (d'Alembert 1747) on the basis of mathematical expression developed by Le- 
onhard Euler (1707-1783) (Euler 1750) and later developed by Joseph-Louis Lagrange (1736-1813) (Lagrange 1760). The development of the necessary mathematical tools for analysing sound waves by Leonhard Euler, d' Alembert, and Lagrange contributed to the understanding of the vibration of major components of musical instruments such as strings, rods, membranes, plates, and organ pipes. Sound spreads across many facets of human, life and society, e.g. music, architecture, industry. In music, harmony of sounds is an important feature, which means playing multiple notes simultaneously or playing notes in a particular sequence that makes sounds pleasing to the ear. Harmony also defines a relationship between musical tones and perception of human. Thus harmony became a musical term. Such relationships are expressible through elementary scientific investigations that lead to an optimal performance of the combination of the notes. Musical harmony has been the inspiration behind a new class of nature-inspired computing known as harmony search (Siddique, Adeli 2015a). Siddique and Adeli (2015b) present a review of applications of harmony search algorithms in engineering. Siddique and Adeli (2015c) present a review of hybrid harmony search algorithms. The idea of hybridization is to enhance the solution accuracy and convergence rate through integration with other natureinspired computing approaches such as genetic algorithm (GA) (Zhu et al. 2014), particle swarm optimization (PSO) (Zeng et al. 2014; Shabbir, Omenzetter 2015), and Ant Colony Optimization (ACO) (Forcael et al. 2014).

\subsection{Hydrology and dynamics}

The concept of hydrologic cycle in the antiquity concerned with the waters of the earth, its circulation, distribution and properties was erroneous from a scientific point of view. The Greek philosopher Anaxagoras of Clazomenae (500-428 BC) possibly gave the first primitive concept of hydrologic cycle (Koutsoyiannis, Angelakis 2003). His concept was that the sun evaporates water from the sea into atmosphere and then water falls as rains onto earth. Rain water is deposited in underground reservoirs and feeds the rivers to flow. An improved concept of hydrologic cycle was given by Theophrastus (372-287 BC) (Koutsoyiannis, Angelakis 2003). Further development was achieved by Roman architect and engineer Marcus Vitruvius (believed to have lived during the time of Jesus Christ) who conceived a theory which is accepted in the modern view (see Vitruvius 1826). He suggested that ground water is derived from rain and snow through infiltration from ground surface. The new concept of hydrologic cycle is based on the dynamical sequential system theory where the inputs are the rain, snow falls, and ground water and the outputs are the evapotranspiration, infiltration and runoff. The throughput is the water moving through the watersheds under the influence of gravitation towards the ocean. Applying system theoretic concepts, the hydrologic cycle can be better analysed and its dynamic and optimal behaviour can be better predicted. A number of approaches have been devised based on the principles of hydrologic cycle such as water drop algorithm (Siddique, Adeli 2014a), river formation dynamics (Rabanal et al. 2007), and water cycle algorithm (Eskandar et al. 2012; Siqueira et al. 2014).

The phenomena observed in particles, atoms, matter, solar systems and galaxies seem to be similar and coherent - all in motion under the influence of gravitation and adhering to an order. The fundamental postulates of the dialectics of nature are based on the matter and its motion, on time and space, which seeks equilibrium of forces and energy to maintain stability. These natural phenomena of gravitation, electrostatic, electromagnetic, thermodynamic, optical and hydrodynamic can be seen as conditions of optimality in the nature with its altruism. Researchers of different disciplines of science, engineering and technology have been exploring these features to develop models, methods, algorithms, optimisation and computational procedures. For example, the spiral pattern is found extensively in nature, encoded into plants, animals, weather phenomena, the earth, and galaxies around us. This has been the inspiration behind spiral dynamics optimization algorithms (Siddique, Adeli 2014b).

\section{Development in chemistry}

There are many wonders of chemistry. The great strength of diamond, the most expensive stone and the hardest material, comes from the tetragonal spatial structure of carbon. Plant leaves are green because of chlorophyll, a key component in photosynthesis, which lets plants use energy from sunlight to convert water and carbon dioxide into sugars. Fire flames comprising carbon dioxide, water vapour, oxygen and nitrogen provide heat and light. All these are simple examples of chemical reactions found in the nature. At the birth of the planet, there can be no question of chemical compounds at such high temperature like that of the sun. With progressive cooling the interplay of the physical forms of motion become transformed into one another. It gradually reached a point from where chemical affinity began developing. The previously chemically indifferent elements became differentiated chemically one after another. They acquired chemical properties and entered into combination with one another. These compounds changed continually with decreasing temperature which affected differently not only each element but also each separate compound of the elements, changing from gaseous matter first into liquid and then solid state with the new conditions thus created (Engels 1934).

The history of chemistry dates back to period of alchemy which had been practiced for millennia in various parts of the world. The alchemists considered four classical elements in phlogiston theory: fire, water, air, and earth. Johann Joachim Becher (1635-1682) proposed three forms of earth by eliminating fire, water, and air from the classical element model and replaced them with three forms of earth: terra lapidea, terra fluida, and terra 
pinguis (Bowler 2005). The element Terra pinguis was oily, sulphurous, and had the properties that help combustion (Brock 1993). Becher believed that terra pinguis was a key feature of combustion and was released when combustible substances were burned (Bowler 2005). Later Georg Ernst Stahl proposed a variant of the theory and renamed Becher's terra pinguis to phlogiston in 1703. The theory dominated chemistry during the first half of the eighteenth century. Antoine Laurent Lavoisier (1743-1794) first disproved the phlogiston theory widely popular among scientist around that time and emancipated chemistry from alchemy (Bensaude-Vincent 2003; see Lavoisier 1787). The law of conservation of mass is also discovered by Lavoisier which was of immense importance in the progress of chemistry. The law of conservation of mass states that the mass of a system must remain constant over time, that is, the mass can neither be created nor be destroyed. It may be changed from one form to another. John Dalton (1766-1844) was the first to realize the existence of elementary atoms (Dalton $1808,1810,1827)$. He postulated that groups of atoms disassociate and then rejoin in new arrangements during chemical reactions. Atomic structure constrains different atoms to form groups in fixed ways as molecules. A molecule comprising several atoms is characterized by the atom type, bond, and angle, which is termed by molecular structure. With this information, a definition of chemical reaction can be provided.

In a chemical reaction chemical bonds are broken by absorption of energy and new bonds are formed with release of energy. A chemical reaction comprises of different types of unimolecular and multi-molecular elementary reactions, each of which releases or absorbs different level of energies. A reaction can be seen as a process of structural change in molecule. This definition includes all processes including process of change of substance and change of forms. In that sense, freezing of water is also to be considered as a chemical reaction. Based on the exchange of energy, chemical reactions are classified into three types: exothermic (when overall, energy is released), endothermic (when overall energy is absorbed) and athermic (when no energy is exchanged) (Waldram 1987). In general, reactions require the introduction of energy in some form, e.g. heat or light, from an external source. According to the theories of Max Planck and Albert Einstein, light is also energy comprising of discrete particles called photons. It is now known that it is the energy relationship that accelerates or retards chemical reactions. Entropy is a measure of energy, which also causes a chemical reaction to happen. Entropy also represents the measure of the disorder in the system. In a chemical reaction process, a population of reactants with high-energy level and unstable states (i.e. molecules of different structures) undergo a sequence of elementary chemical reactions, transform through different energy levels and produce certain products (i.e. molecules of new structures) of low-energy and stable states at the final stage. Above all of these, chemical reactions tend to achieve equilibrium of energy, an optimal or stable state. The process of the chemical reaction is therefore seen as an optimisation process. A number of computing and optimisation algorithms have been developed based on the principles of chemical reaction, for example, the Artificial Chemical Process Algorithm (Irizarry 2004) and Chemical Reaction Optimization (Lam, Li 2010). Environmentally sustainable design is currently a very active area of research (Wang, Adeli 2014). Szeto et al. (2014) use a chemical reaction optimization approach to solve the environmentally sustainable network design problem.

\section{Development in biology}

Life introduces a degree of order, organisation, and diversity on the earth which is not yet found elsewhere in the universe. Life on earth is not due to a sudden event rather a result of natural evolution, which created the immense diversity of species.

In the antiquity, Aristotle (384-322 BC) showed interest in zoology as fish was of extreme economic importance in Greece at the time. His view of classification was roughly near to that of the modern evolutionist. It ran from lower plants to higher plants through molluscs, arthropods, reptiles, birds, and fishes, mammals and men. His student Theophrastus (380-287 BC) did the same work in botany. The biological sciences emerged from traditions of medicine and natural history reaching back to Ayurveda, ancient Egyptian medicine and the works of Aristotle and Galen (130-200 AD) in the ancient GrecoRoman world. In the middle ages, great work in biological science was done by the great Persian scholar Avicenna $^{9}$ (980-1037), which was later translated into Latin for Europeans (Pledge 1939).

Biological science was revolutionized during the European Renaissance and by many discoveries in the early modern period. Cells are easiest to see in plants which were discovered by Grew and Malpighi and the cell theory started being developed in the $17^{\text {th }}$ century. Antonie Philips van Leeuwenhoek (1632-1723) became well-known for his contribution to the development of microscope (Pledge 1939). He was able to see a thing much smaller than cell. He was known for the discovery of single-cell organism. Robert Brown's (1773-1858) contribution was the earliest description of cell nucleus (Pledge 1939).

In the 18th century biologists were busy collecting and sifting through the vast botanical, zoological, anatomical, and physiological samples, and naming and classifying the dominating natural history. Scientists were

9 Ibn Sina was a Persian scholar and scientist known as Avicenna in the West. Among his famous works are the two books "The Book of Healing" and "The Canon of Medicine", which became a standard medical text during medieval age and as late as 1650. The book "Canon of Medicine" was reprinted in New York in 1973. 
busy with the essential investigation and comparison of various forms of life, geographical distribution, condition of existence, and climate. Botany and zoology arrived around the same time owing to Carl Linnaeus (17071778 ) in the years between 1750s and 1760s (Linnaeus 1758; Pledge 1939).

The efforts continued following improvements of microscope in the early years of $19^{\text {th }}$ century. Matthias Jacob Schleiden (1804-1881) published his cell theory in 1838 applying it throughout the plant kingdom (Schleiden 1838). Cells were seen as central to life. Theodor Schwann (1810-1882) announced the general theory of the cell as the basis of life in 1839 (Schwann 1839). Tissues (both plant and animal) are built up with various combinations of cells. The cell theory of Schleiden and Schwann had two important contributions to biological science: the first one was the microscopic creatures responsible for putrefaction, fermentation and disease, and the second one was the cell division responsible for growth and reproduction. Jan Evangelista Purkyně (1787-1869) discovered Purkinje cell in 1837 and coined the term protoplasm for the fluid substance in cell (Pledge 1939). Hugo von Mohl (1805-1872) distinguished the protoplasm from the sap of vegetable cells in 1846 and showed that the protoplasm is the source of those movements in cells (Pledge 1939). This was the excitement of the time and attracted much attention. Thomas Huxley (1825-1895) referred to protoplasm as the physical basis of life which considered that the property of life resulted from the distribution of molecules within this substance (Harvey 2004).

Jean-Baptiste Pierre Antoine de Monet, Chevalier de Lamarck (1744-1829), known as Lamarck, postulated that environmental influences such as climatic, nutritive, behavioural etc. are transmitted to the next generation (Lamarck 1809). Lamarck's contribution was the truly cohesive theory of evolution of inheritance of acquired characteristics. Gregor Johann Mendel (1822-1884) established many of the rules of heredity based on his pea plant experiments conducted between 1856 and 1863 which are now referred to as the laws of Mendelian inheritance (Mendel 1866).

Much of the beauty and diversity of life on earth is due to sex. An asexual organism would require frequent mutation for adaptation and diversity. The chance of an adaptation in asexual organism then requires the mutations to wait for an accidental event. The sex solves this problem in an elegant way by re-assorting the genetic material of the parents that produce completely new offspring with diverse combinations of genes. Some organisms developed more than two sexes. For example paramecia have somewhere between five and ten sexes and can combine their genetic material.

Energy must be supplied to living organisms. Organisms acquire this energy in two general ways. Some organisms (e.g. heterotrophs) acquire energy by controlled breakdown of organic molecules, i.e. food, supplied by other organisms. Human and most animals are heterotrophs. Some organisms, known as autotrophs, acquire their energy from other sources, either from the energy of sunlight (in this case organisms are called photoautotrophs) or from controlled chemical reaction of inorganic materials (in this case organisms are called chemoautotrophs). These facts provide evidence for the direct relationship between energy and the very existence and survival of life. The largest of all providers of energy is the Sun of our solar system which is not equally distributed all over the regions on the earth causing different climatic and geographic conditions.

Georges-Louis Buffon (1707-1788) first noticed that the average patterns of distribution of the flora, fauna, and vegetation seemingly vary across geographic regions (Buffon 1766). The present distribution patterns of plants and animals are the results of climatic and geographic conditions, geological history of climates and landmasses and evolutionary history of the species. MacArthur and Wilson (1967) studied the geographical areas that are well suited as residences for biological species. These geographical areas are said to have a high habitat suitability index (HSI). Features that correlate with HSI include factors such as rainfall, diversity of vegetation, diversity of topographic features, land area, and temperature. The variables that characterize habitability are called suitability index variables (SIVs). SIVs can be considered the independent variables of the habitat, and HSI can be considered the dependent variable (MacArthur, Wilson 1967). MacArthur and Wilson (1967) tried to develop mathematical models of biogeography that describe the relationship between SIVs and HIS. Biogeography is the study of the geographical distribution of biological species.

The excellent scientific evidence behind this emergence of man was discerned by Charles Darwin (18091882) by publishing his ground-breaking work, the Origin of Species, in 1859 (Darwin 1859). A modern rephrasing of his theory is that organisms slowly evolve toward greater complexity through adaptation and adaptation itself is a mechanism accomplished by natural selection. $\mathrm{He}$ established that all species of life have descended over time from common ancestors.

Biology has been an inspiration of many ground breaking inventions since $19^{\text {th }}$ century. The paradigm of biology-based algorithms is huge and diverse in many aspects. It forms a broader class of search and optimization algorithms. These algorithms can be classified into three broad groups: evolutionary algorithms, bio-inspired algorithms and swarm intelligence-based algorithms (Siddique, Adeli 2015e). The evolutionary algorithms have been covered in a recent book by Siddique and Adeli (2013).

\section{Final remarks}

The natural sciences had begun to flourish in the twentieth century in a remarkable way with many applications in engineering, technology, industry, economy, and so- 
ciety. The activities of science have become multifarious and specialised and scientific literature has become voluminous. Developing computing methods, algorithms, and ideas mimicking or imitating the behaviours or phenomena of nature for solving complex problems is termed natured-inspired computing (Shadbolt 2004). Nature-inspired concepts and ideas have great potential for developing methods and algorithms to tackle seemingly intractable engineering problems.

In the process of evolution whether it is living or non-living, it has to satisfy a set of criteria to survive or move to the next stage of development. In a similar fashion, designing systems requires satisfying specific criteria such as economic or material constraints. The problem of optimality then became one of the key issues in designing systems. In fact, the problem of optimality is a central issue in science, engineering, economy and everyday life. The conditions of optimality only define local extrema. If the number of such extrema is large, the problem of finding the global extremum becomes a complex problem. Various clever algorithms, mathematical approaches and derivative-based optimisation techniques have been developed over the past many decades. These algorithms seem to work out well up to certain level of complexity of the problems. As the complexity of problems grows, the efficiency and appeal of these algorithms or approaches become unsatisfactory Furthermore, many real-life optimisation problems have constraints that either cannot be defined mathematically or are highly nonlinear implicit and discontinuous functions of design variables. Therefore, the search for unconventional algorithms and the identification of problems to which each of the methods (deterministic or stochastic) is suitable for has to be pursued, together with an understanding of why and how they work or not. There arose the need for non-traditional approaches that are inspired by nature such as physical, chemical, biological phenomena and evolution observed in nature. Most of these phenomena have been well studied under different disciplines of natural sciences and can be well explained with the notion of dialectics of nature. These facts lead many researchers to apply natureinspired techniques to optimisation problems in engineering, economics, science and technology that also enable searching a high-dimensional space.

Darwin's work is the inspiration behind evolutionary computing and genetic algorithms used extensively in two broad areas of adaptive optimization and learning (Adeli, Hung 1995; Mesejo et al. 2015) with applications in a variety of domains in the past three decades. Examples include time-cost tradeoff analysis in a construction schedule, production-distribution planning (Jia et al. 2014), sustainable process planning and scheduling (Li et al. 2015), automatic learning of image filters (Paris et al. 2015), design optimization of counterrotating compressors (Joly et al. 2014), design of wireless networks (Molina-García et al. 2014), and development of a clustering algorithm (Menendez et al. 2014).
There are numerous examples from our lonely planet earth and the biological world with immense diversity of species. The swarm systems in nature are perhaps one of the most charming things to observe. A flock of birds twisting in the evening light, v-shaped structure of the migrating geese, winter birds hunting for food, dancing of starlings in the evening light, ants marching for foraging, synchronized flashing of fireflies and mound building by termites are some of the fascinating examples of swarm systems. But how do they produce such collective behaviour without any central coordinator or leader? How do they communicate with each other? How a bee which has found food does tell other bees about the location of the food? How do the flocks of migrating geese maintain a v-shaped structure? How do even the fireflies know when to glow? Is there a central control or coordinator for the collective behaviours? The philosophers, scientists and biologists have been trying over centuries to explain these phenomena. The visible phenomena appear to be the result of thousands of invisible, known and unknown causes. These natural phenomena have provided the inspiration for nature-inspired optimization algorithm such as PSO mentioned earlier (Boulkabeit et al. 2014; Iacca et al. 2014).

\section{References}

Adeli, H.; Hung, S. L. 1995. Machine learning - neural networks, genetic algorithms, and fuzzy systems. New York: John Wiley and Sons.

Ampere, A.-M. 1820. Memoir on the mutual action of two electric currents, Annales de Chimie et Physique, Vol. 15. $59 \mathrm{p}$.

Anderson, K. 1983. The mathematical techniques in Fermat's deduction of the law of refraction, Historia Mathematica 10: 48-62. http://dx.doi.org/10.1016/0315-0860(83)90032-0

Andriesse, C. D. 2005. Huygens: the man behind the principle. Cambridge: Cambridge University Press.

Buffon, G. L. L. 1766. Histoire Naturelle, générale et particulière, avec la description du Cabinet du Roi. Paris: Imprimerie Royale.

Bensaude-Vincent, B. 2003. Languages in chemistry, Chapter 9 , in M. J. Nye (Ed.). The Cambridge history of science, vol. 5: The modern physical and mathematical sciences. Cambridge University Press. http://dx.doi.org/10.1017/CHOL9780521571999

Biot, J.-B.; Savart, F. 1820. Note sur le magnétisme de la pile de Volta, Annales de Chimie et Physique 15: 222-223 (in French).

Birbil, S. I.; Fang, S. C. 2003. An electromagnetism-like mechanism for global optimization, Journal of Global Optimization 25(3): 263-282.

http://dx.doi.org/10.1023/A:1022452626305

Boulkabeit, I.; Mthembu, L.; De Lima Neto, F.; Marwala, T. 2014. Finite element model updating using Fish School search and volitive particle swarm optimization, Integrated Computer-Aided Engineering 22(4): 361-376. http://dx.doi.org/10.3233/ICA-150495

Bowler, P. J. 2005. Making modern science: a historical survey. Chicago: University of Chicago Press.

http://dx.doi.org/10.7208/chicago/9780226068626.001.0001

Boyer, C. B. 1991. A history of mathematics. $2^{\text {nd }} \mathrm{ed}$. Revised by U. C. Merzbach. John Wiley and Sons. 
Brasch, F. E. 1931. Johann Kepler 1571-1630: a tercentenary commemoration of his life and works. Baltimore: Williams and Wilkins.

Brock, W. H. 1993. The Norton history of chemistry. $1^{\text {st }}$ American ed. W. W. New York: Norton.

Carnot, S. 1824. Reflections on the motive power of fire and other papers on the second law of thermodynamics. English translation by R. H. Thurston, 1960. New York: Dover.

Cercignani, C. 1998. Ludwig Boltzmann: the man who trusted atoms. Oxford: Oxford University Press.

Child, J. M. 1920. The early mathematical manuscript of Leibnitz. Ed., translated by C. I. Gerhardt. Chicago: Open Court.

Chuang, C.; Jiang, J. 2007. Integrated radiation optimization: inspired by the gravitational radiation in the curvature of space-time, in IEEE Congress on Evolutionary Computation (CEC), 25-28 September 2007, Singapore, 31573164. http://dx.doi.org/10.1109/cec.2007.4424875

Cohen, I. B. 1971. Introduction to Newton's principia. Cambridge: Cambridge University Press. http://dx.doi.org/10.4159/harvard.9780674283619

D'Alembert, J. R. 1747. Recherches sur la courbe que forme une corde tendue mise en vibration [Researches on the curve that a tense cord forms when set into vibration], Histoire de l'académie royale des sciences et belles lettres de Berlin 3: 214-219.

Dalton, J. 1808. A new system of chemical philosophy, Vol. 1, Part 1. R. Bickerstaff, Manchester.

Dalton, J. 1810. A new system of chemical philosophy, Vol. 1, Part 2. R. Bickerstaff, Manchester.

Dalton, J. 1827. A new system of chemical philosophy, Vol. 2. R. Bickerstaff, Manchester.

Darwin, C. 1859. The origin of species by means of natural selection or the preservation of favoured races in the struggle for life. London: John Murray.

Deleforge, A.; Forbes, F.; Horaud, R. 2015. Acoustic space learning for sound-source separation and localization on binaural manifolds, International Journal of Neural Systems 25(1), 1440003. $21 \mathrm{p}$.

Descartes, R. 1954. The geometry. Translated by D. E. Smith, M. L. Latham, Paperback Ed. New York: Dover.

Dickinson, H. W. 1939. A short history of the steam engine. Cambridge: Cambridge University Press.

Drake, S. 1973. Mathematics and discovery in Galileo's physics, Historia Mathematica 1: 129-150. http://dx.doi.org/10.1016/0315-0860(74)90002-0

Elliott, R. S. 1993. Electromagnetics. Piscatway, NJ: IEEE Press.

Einstein, A. 1905. Über einen die Erzeugung und Verwandlung des Lichtes betreffenden heuristischen Gesichtspunkt, $\mathrm{An}$ nalen der Physik 17(6): 132-148 (in German). http://dx.doi.org/10.1002/andp.19053220607

Einstein, A. 1915. Die Feldgleichungun der Gravitation, in Sitzungsberichte der Preussischen Akademie der Wissenschaften zu Berlin, 844-847 (in German).

Einstein, A. 1916. The foundation of the General Theory of Relativity, Annalen der Physik 354(7): 769-822. http://dx.doi.org/10.1002/andp.19163540702

Einstein, A. 1918. Über Gravitationswellen, in Sitzungsberichte der Königlich Preussischen Akademie der Wissenschaften Berlin, Part 1, 154-167.

Eisberg, J. 2003. Solar Science and Astrophysics, Chapter 26, in M. J. Nye (Ed.). The Cambridge history of science, Vol. 5: The modern physical and mathematical sciences. Cambridge: Cambridge University Press.

Engels, F. 1934. Dialectics of nature. $5^{\text {th }}$ ed. Moscow: Progress Publishers.
Erol, O. K.; Eksin, I. 2006. A new optimization method: Big Bang-Big Crunch, Advances in Engineering Software 37(2): 106-111.

http://dx.doi.org/10.1016/j.advengsoft.2005.04.005

Eskandar, H.; Sadollah, A.; Bahreininejad, A.; Hamdi, M. 2012. Water cycle algorithm - a novel metaheuristic optimization method for solving constrained engineering optimization problems, Computers \& Structures 110-111: 151166. http://dx.doi.org/10.1016/j.compstruc.2012.07.010

Euler, L. 1750. Sur la Vibration des Cordes [On the Vibration of Strings], Memoires de l'academie des sciences de Berlin 4: 69-85.

Faraday, M. 1855. Experimental researches in electricity, Vol. 3, Art. 3249. London: Bernard Quatrich.

Forcael, E.; González, V.; Orozco, F.; Vargas, S.; Moscoso, P.; Pantoja, A. 2014. Ant colony optimization model for Tsunamis evacuation routes, Computer-Aided Civil and Infrastructure Engineering 29(10): 723-737. http://dx.doi.org/10.1111/mice.12113

Forbes, E. G. 1977. Descartes and the birth of analytical geometry, Historia Mathematica 4: 141-151. http://dx.doi.org/10.1016/0315-0860(77)90105-7

Fraser, C. 1983. J. L. Langrange's early contributions to the principles and methods of mechanics, Archive for History of Exact Sciences 28: 197-241. http://dx.doi.org/10.1007/BF00328268

Friedmann, A. 1922. Ueber die Kruemmung des Raumes, Zeitschrift fuer Physik 10: 377-386. http://dx.doi.org/10.1007/BF01332580

Galilei, G. 1960. On motion, on mechanics. Madison, Wisc.: University of Wisconsin Press.

Gilbert, W. 1600. De Magnete, translated by P. Fleury Mottelay. On the Lodestone and Magnetic Bodies 1893. John Wiley \& Sons.

Gillespie, C. C. 1971. Lazare Carnot Savant. Princeton: Princeton University Press.

Gillmor, C. S. 1971. Coulomb and the evolution of physics and engineering in the eighteenth century France. Princeton, NJ: Princeton University Press.

Grattan-Guinness, I. 1971. The development of the foundations of mathematical analysis from Euler to Riemann. Cambridge: MIT Press.

Grattan-Guinness, I. 1972. Joseph Fourier 1768-1830. Cambridge: MIT Press.

Grove, W. R. 1874. The correlation of physical forces. $6^{\text {th }}$ ed. London: Longmans, Green. http://dx.doi.org/10.5962/bhl.title.19475

Gupta, M. S. 1980. George Simon Ohm and Ohm's Law, IEEE Transaction on Education 23(3): 156-162. http://dx.doi.org/10.1109/TE.1980.4321401

Hallyn, F. 1993. The poetic structure of the world: Copernicus and Kepler. Translated by D. M. Leslie. New York: Zone Books.

Harvey, E. N. 2004. Some physical properties of protoplasm, Journal of Applied Physics 9(2): 68. http://dx.doi.org/10.1063/1.1710397

Hatamlou, A. 2013. Black hole: a new heuristic optimization approach for data clustering, Information Sciences 222: 175-184. http://dx.doi.org/10.1016/j.ins.2012.08.023

Hawking, S. 1998. A brief history of time - from the Big Bang to Black hole. London: Bantam Press.

Helmholtz, H. 1871. Ueber die Wechselwirkung der Naturkraefte, Ein populaerwissenschaftlicher Vortrag in Koenigberg in Prussen, 2. Heft, Vieweg, Braunschweig.

Hertz, H. R. 1888. Ueber die Ausbreitungsgeschwindigkeit der electrodynamischen Wirkungen, Annalen der Physik 270(7): 551569. http://dx.doi.org/10.1002/andp.18882700708 
Hobson, E. W. 1914. John Napier and the invention of logarithms, 1614. Cambridge: The University Press.

Hosseini, H. S. 2011. Principal component analysis by Galaxybased search algorithm: a novel meta-heuristic for continuous optimisation, International Journal of Computational Science and Engineering 6(1-2): 132-140. http://dx.doi.org/10.1504/IJCSE.2011.041221

Hubble, E. 1929. A relation between distance and radial velocity among extra-galactic nebulae, in Proceedings of the National Academy of Sciences of the United States of America (PNAS) 15(3): 168-173. http://dx.doi.org/10.1073/pnas.15.3.168

Hubble, E. P. 1936. The realm of the Nebulae. New Haven: Yale University Press.

Hunt, B. J. 2003. Electrical theory and practice in the nineteenth century, Chapter 17, in M. J. Nye (Ed.). The Cambridge history of science, Vol. 5: The modern physical and mathematical sciences. Cambridge University Press.

Hsiao, Y. T.; Chuang, C. L.; Jiang, J. A.; Chien, C. C. 2005. A novel optimization algorithm: Space Gravitational Optimization, in Proc. of 2005 IEEE International Conference on Systems, Man and Cybernetics, October 2005, Waikoloa, HI, USA, 3: 2323-2328.

http://dx.doi.org/10.1109/ICSMC.2005.1571495

Iacca, G.; Caraffini, F.; Neri, F. 2014. Multi-strategy coevolving aging particle optimization, International Journal of Neural Systems 24(1), 1450008. 19 p.

Inan, U. S.; Inan, A. S. 1999. Engineering electromagnetics. California: Addison-Wesley Longman Inc.

Irizarry, R. 2004. LARES: an artificial chemical process approach for optimization, Evolutionary Computation Journal 12(4): 435-459. http://dx.doi.org/10.1162/1063656043138897

Jia, L.; Wang, Y.; Fan, L. 2014. Multiobjective bilevel optimization for production-distribution planning problems using hybrid genetic algorithm, Integrated Computer-Aided Engineering 21(1): 77-90.

Joly, M. M.; Verstraete, T.; Paniagua, G. 2014. Integrated multifidelity, multidisciplinary evolutionary design optimization of counterrotating compressors, Integrated ComputerAided Engineering 21(3): 249-261.

Joule, J. P. 1841. On the heat evolved by metalic conductors of electricity, Philosophical Magazine 19: 260-265.

Joule, J. P. 1850. On the mechanical equivalent of heat, Philosophical Transactions of the Royal Society of London 140: 61-82. http://dx.doi.org/10.1098/rstl.1850.0004

Jourdian, P. E. B. 1912. Note on Fourier's influence on the conceptions of mathematics, in International Congress of Mathematicians, 1912, Cambridge, England, 2: 526-527.

Kant, I. 1781. Universal natural history and theory of the heavens. Translated by S. Palmquist in Kant's Critical Religion, 2000. Aldershot: Ashgate.

Kaveh, A.; Khayatazad, M. 2012. A new meta-heuristic method: Ray optimization, Computers \& Structures 112-113: 283294. http://dx.doi.org/10.1016/j.compstruc.2012.09.003

Koutsoyiannis, D.; Angelakis, A. N. 2003. Hydrologic and hydraulic sciences and technologies in ancient Greek times, in B. A. Stewart, T. Howell (Eds.). The encyclopaedia of water science. NY, USA: Markel Dekker Inc., 415-418.

Lagrange, J. L. 1901. Lectures on elementary mathematics. Translated by T. J. McCormack. Chicago: Open Court.

Lagrange, J. L. 1760. Nouvelles Recherches sur la Natuer et la Propagation du Son, Miscellanea Taurenencia 2: 11-172.

Lam, A. Y. S.; Li, V. O. K. 2010. Chemical-reaction-inspired meta-heuristic for optimization, IEEE Transaction on Evolutionary Computation 14(3): 381-399. http://dx.doi.org/10.1109/TEVC.2009.2033580

Lamarck, J.-B. 1809. Philosophie Zoologique. New ed. Paris: Germer Baillière (in French).
Laplace, P. S. 1966. Mecanique Celeste. Translated and Ed. by N. Bowditch. 4 Vols Reprint of the 1829-1839 ed. Chelsea, New York.

Lavoisier, A. L. 1787. Mémoire sur la necessite de reformer et de perfectionner la nomenclature de la Chimie, Methode de Nomenclature, 1-25.

Leibnitz, G. W. 1975 [1686]. Energy - historical development of the concept. English Translation by R. B Lindsay, D. Hutchinson, R. Stroudberg.

Li, X. X.; Li, W. D.; Cai, X. T.; He, F. Z. 2015. A hybrid optimization approach for sustainable process planning and scheduling, Integrated Computer-Aided Engineering 22(4): 311-326. http://dx.doi.org/10.3233/ICA-150492

Linnaeus, C. 1758. Systema naturae. 10th ed. Stockholm: Laurentius Salvius.

MacArthur, R.; Wilson, E. 1967. Theory of biogeography. Princeton, NJ: Princeton University Press.

Marco, B. 1998. Medicine and science in the life of Luigi Galvani, Brain Research Bulletin 46(5): 367-380. http://dx.doi.org/10.1016/S0361-9230(98)00023-9

Maxwell, J. C. 1892. A Treatise on Electricity and magnetism. Oxford: Clarendon Press.

Maxwell, J. C. 1865. A dynamical theory of the electromagnetic field, Philosophical Transaction of Royal Society, Vol. 155. London, UK. 450 p.

Mayer, J. R. 1842. Bemerkungen ueber die Kraefte der unbelebten Natur, Liebig's Annalen der Chemie und Phramazie, Vol. 42.239 p.

Mendel, J. G. 1866. Versuche über Pflanzenhybriden. Verhandlungen des naturforschenden Vereines in Brünn, Band IV für das Jahr, 1865 Abhandlungen, 3-47. For the English translation see: Druery, C. T.; Bateson, W. 1901. Experiments in plant hybridization, Journal of the Royal Horticultural Society 26: 1-32.

Menendez, H.; Barrero, D. F.; Camacho, D. 2014. A genetic graph-based approach to the partitional clustering, International Journal of Neural Systems 24(3), 1430008. 19 p.

Mesejo, P.; Fernandez-Blanco, O. I. E.; Cedron, F.; Pazos, A.; Porto-Pazos, A. B. 2015. Artificial neuron-glia networks learning paradigm based on cooperative coevolution, International Journal of Neural Systems 25(4), 1550012. $19 \mathrm{p}$.

Molina-García, M.; Calle-Sánchez, J.; González-Merino, C.; Fernández-Durán, A.; Alonso, J. I. 2014. Design of inbuilding wireless networks deployments using evolutionary algorithms, Integrated Computer-Aided Engineering 21(4): 367-385.

Napier, J. 1969. A description of the admirable table of logarithms. Amsterdam, New York: Theathrum Orbis Terrarum, Da Capo Press.

Newton, I. 1972. Isaac Newton's philosophiae naturalis mathematica. A. Koyre, I. B. Cohen (Eds.). $3^{\text {rd }}$ ed. with variant readings, 2 Vols. Cambridge: Cambridge University Press.

Newton, I. 1999. The Principia: mathematical principles of natural philosophy. Translation by I. B. Cohen, J. Budenz, A. Whitman Miller. Berkeley, California: University of California Press.

Oerstedt, H. C. 1820. Experiments on the effect of current of electricity on the magnetic needle, English translation in Annals of Philosophy, Vol. 16. 273 p.

Oppenheimer, J. R.; Snyder, H. 1939. On continued gravitational contraction, Physical Review 56(5): 455-459. http://dx.doi.org/10.1103/PhysRev.56.455

Pancaldi, G. 2003. Volta: science and culture in the age of enlightenment. Princeton University Press, NJ.

Paris, P. C. D.; Pedrino, E. C.; Nicoletti, M. C. 2015. Automatic learning of image filters using Cartesian genetic programming, Integrated Computer-Aided Engineering 22(2): 135-151. 
Planck, M. 1900a. Ueber eine Verbesserung des Wienschen Spektralgleichung, Verhandlungen der Deutschen Physikalische Gesellschaft 2: 202-204.

Planck, M. 1900b. Zur Theorie des Gesetzen der Energieverteilung im Normalspektrum, Verhandlungen der Deutschen Physikalische Gesellschaft 2: 237-245.

Pledge, H. T. 1939. Science since 1500: a short history of mathematics, physics, chemistry and biology. London: Ten Shillings Net.

Rabanal, P.; Rodríguez, I.; Rubio, F. 2007. Using river formation dynamics to design heuristic algorithms, in Unconventional Computation, UC'07, LNCS 4618, 13-17 August 2007, Kingston, Canada. Springer, 163-177.

Sandage, A. 1975. Galaxies and universe-stars and stellar systems. Chicago: University of Chicago Press.

Schaffer, S. 1979. John Michell and black holes, Journal for the History of Astronomy 10: 42-43. http://dx.doi.org/10.1177/002182867901000104

Schleiden, M. J. 1838. Beiträge zur Phytogenesis, Archiv für Anatomie, Physiologie und wissenschaftliche Medicin, 137-176.

Schwann, T. 1839. Mikroskopische Untersuchungen über die Uebereinstimmung in der Struktur und dem Wachsthum der Tiere und Pflanzen. Berlin: Sander.

Schwarzschild, K. 1916. Über das Gravitationsfeld eines Massenpunktes nach der Einsteinschen Theorie, Sitzungsberichte der Königlich-Preussischen Akademie der Wissenschaften, Sitzung 3. Februar 1916, Deutsche Akademie der Wissenschaften zu Berlin, 189-196 (in German).

Shabbir, F.; Omenzetter, P. 2015. Particle swarm optimization with sequential niche technique for dynamic finite element model updating, Computer-Aided Civil and Infrastructure Engineering 30(5): 359-375.

http://dx.doi.org/10.1111/mice. 12100

Shadbolt, N. 2004. Nature-inspired computing, IEEE Intelligent Systems 19(1): 2-3. http://dx.doi.org/10.1109/MIS.2004.1265875

Siddique, N.; Adeli, H. 2013. Computational intelligence: synergies of fuzzy logic, neural networks and evolutionary computing. Chichester, UK: John Wiley and Sons. http://dx.doi.org/10.1002/9781118534823

Siddique, N. H.; Adeli, H. 2014a. Water drop algorithms, International Journal on Artificial Intelligence Tools 23(6), 1430002. $22 \mathrm{p}$.

Siddique, N. H.; Adeli, H. 2014b. Spiral dynamics algorithm, International Journal on Artificial Intelligence Tools 23(6), 1430001. 24 p.

Siddique, N.; Adeli, H. 2015a. Harmony search algorithm and its variants, International Journal of Pattern Recognition and Artificial Intelligence 29(8), 1539001. 22 p.

Siddique, N.; Adeli, H. 2015b. Applications of harmony search algorithms in engineering, International Journal on Artificial Intelligence Tools 24(6), 1530002. 15 p.

Siddique, N.; Adeli, H. 2015c. Hybrid harmony search algorithms, International Journal on Artificial Intelligence Tools 24(6), 1530001. $16 \mathrm{p}$.

Siddique, N.; Adeli, H. 2015d. Central force metaheuristic optimization, Scientia Iranica - Transaction A: Civil Engineering 22(6): 1941-1953 (Invited paper).
Siddique, N.; Adeli, H. 2015e. Nature-inspired computing: an overview and some future directions, Cognitive Computation 7(6): 706-714.

http://dx.doi.org/10.1007/s12559-015-9370-8

Siddique, N. H.; Adeli, H. 2016a. Gravitational search algorithm and its variants, International Journal of Pattern Recognition and Artificial Intelligence. To be published.

Siddique, N.; Adeli, H. 2016b. Nature inspired computing: physics and chemistry based algorithms. CRC Press, Taylor \& Francis (in press).

Siqueira, H.; Boccato, L.; Attux, R.; Lyra, C. 2014. Unorganized machines for seasonal stream flow series forecasting, International Journal of Neural Systems 24(3), 1430009. $16 \mathrm{p}$.

Spears, D. F.; Spears, W. M. 2003. Analysis of a phase transition in a physics-based multiagent system, Lecture Notes in Computer Science 2699: 193-207. http://dx.doi.org/10.1007/978-3-540-45133-4 16

Szeto, W. Y.; Wang, Y.; Wong, S. C. 2014. The chemical reaction optimization approach to solving the environmentally sustainable network design problem, Computer-Aided Civil and Infrastructure Engineering 29(2): 140-158. http://dx.doi.org/10.1111/mice.12033

Thompson, B. 1798. An inquiry concerning the source of the heat which is excited by friction, Philosophical Transactions of the Royal Society of London 88: 80-102. http://dx.doi.org/10.1098/rstl.1798.0006

Truesdell, C. A. 1992. Cauchy and the modern mechanics of continua, Revue d'Histoire des Sciences 45(1): 5-24. http://dx.doi.org/10.3406/rhs.1992.4229

Vitruvius, M. 1826. De Architectura. Translated by J. Cwilt. London: Priestley and Weale.

Waldram, J. R. 1987. The theory of thermodynamics. $1^{\text {st }}$ ed. Cambridge University Press.

Wang, N.; Adeli, H. 2014. Sustainable building design, Journal of Civil Engineering and Management 20(1): 1-10. http://dx.doi.org/10.3846/13923730.2013.871330

Weber, W. 1848. Elektrodynamische Maassbestimmungen, Annalen der Physik und Chemie 73(2): 193-240.

Weisberg, J. M.; Taylor, J. H. 2004. Relativistic binary pulsar B1913+16: thirty years of observations and analysis, in Binary Radio Pulsars ASP Conference Series, July 2004.

Zaránd, G.; Pázmándi, F.; Pál, K. F.; Zimányi, G. T. 2002. Hysteretic optimization, Physical Review Letters 89(15): 150201-150204. http://dx.doi.org/10.1103/PhysRevLett.89.150201

Zhu, W.; Hu, H.; Huang, Z. 2014. Calibrating rail transit assignment models with genetic algorithm and automated fare collection data, Computer-Aided Civil and Infrastructure Engineering 29(7): 518-530. http://dx.doi.org/10.1111/mice.12075

Zeng, Z.; Xu, J.; Wu, S.; Shen, M. 2014. Antithetic methodbased particle swarm optimization for a Queuing network problem with fuzzy data in concrete transportation systems, Computer-Aided Civil and Infrastructure Engineering 29(10): 771-800. http://dx.doi.org/10.1111/mice.12111 
Nazmul SIDDIQUE. He is a Lecturer in the School of Computing and Intelligent Systems, University of Ulster. He obtained Dipl.-Ing. degree in Cybernetics from the Dresden University of Technology, Germany, MSc in Computer Science from Bangladesh University of Engineering and Technology and $\mathrm{PhD}$ in Intelligent Control from the Department of Automatic Control and Systems Engineering, University of Sheffield, England. His research interests include: cybernetics, computational intelligence, bio-inspired computing, stochastic systems and vehicular communication. He has published over 130 research papers in the broad area of cybernetics, intelligent control, computational intelligence and robotics including three books. He guest edited eight special issues of reputed journals on Cybernetic Intelligence, Computational Intelligence, Neural Networks and Robotics. He is a Fellow of the Higher Education Academy, a senior member of IEEE and member of different committees of IEEE SMC Society and UK-RI Chapter. He has been involved in organising many national and international conferences and co-edited seven conference proceedings. He is on the editorial board of seven international journals including Editor-in-Chief of the International Journal of Automation and Control Engineering. He secured funding from DEL, DAAD, EU FP7-ICT and Daiwa Anglo-Japanese Foundation.

Hojjat ADELI. He received his PhD from Stanford University in 1976 at the age of 26. He is Professor of Civil, Environmental, and Geodetic Engineering, and by courtesy Professor of Biomedical Engineering, Biomedical Informatics, Electrical and Computer Engineering, Neuroscience, and Neurology at The Ohio State University. He has authored over 530 research and scientific publications in various fields of computer science, engineering, applied mathematics, and medicine including 15 books. In 1998 he received the Distinguished Scholar Award, from The Ohio State University "in recognition of extraordinary accomplishment in research and scholarship". He is the recipient of numerous other awards and honors such as The Ohio State University College of Engineering Lumley Outstanding Research Award (quadruple winner); Peter L. and Clara M. Scott Award for Excellence in Engineering Education, and Charles E. MacQuigg Outstanding Teaching Award, the 2012 IEEE-EMBS Outstanding Paper Award (IEEE Engineering in Medicine and Biology Society), a Special Medal from The Polish Neural Network Society in Recognition of Outstanding Contribution to the Development of Computational Intelligence, Eduardo Renato Caianiello Award for Excellence in Scientific Research from the Italian Society of Neural Networks and an Honorary Doctorate from Vilnius Gediminas Technical University, Lithuania. He is a Distinguished Member of ASCE, and a Fellow of AAAS, IEEE, AIMBE, and American Neurological Association. 